\title{
A new Upper Paleolithic occupation at the site of Tolbor-21 (Mongolia): Site formation, human behavior and implications for the
} regional sequence

Evgeny P. Rybin a,b, ${ }^{*}$, Clea H. Paine c, Arina M. Khatsenovich a, ${ }^{* *}$, Bolorbat Tsedendorj d, Sahra Talamo e,f, Daria V. Marchenko a, William Rendu g, Alexei M. Klementiev a,h, Davakhuu Odsuren d, J. Christopher Gillam i, Byambaa Gunchinsuren d, Nicolas Zwyns e,j,***

\author{
a Institute of Archaeology and Ethnography, Siberian Branch, Russian Academy of Sciences, 17 Lavrentiev Ave., Novosibirsk, 630090, Russia \\ b Altai State University, 61 Lenina Avenue, Barnaul, 656049, Russia \\ c Archaeology Institute, University of the Highlands and Islands, Kirkwall, UK \\ d Institute of Archaeology MAS, 77 Zhukov St., 13343, Ulaanbaatar, Mongolia \\ e Department of Human Evolution, Max Planck Institute for Evolutionary Anthropology, 04103, Leipzig, Germany \\ f Department of Chemistry "G. Ciamician", University of Bologna, Via Selmi, 2, 40126, Bologna, Italy \\ g PACEA CNRS, University of Bordeaux, France
}

$\mathrm{h}$ Institute of the Earth's Crust, Siberian Branch, Russian Academy of Sciences, Russia

i Department of Sociology, Criminology and Anthropology, Winthrop University, Rock Hill, SC, 29733, USA

jDepartment of Anthropology, University of California-Davis, 1 Shields Avenue, Davis, 95616, CA, USA

\section{A BSTRACT}

In Central and East Asia, the Upper Paleolithic dates as early as $45 \mathrm{ka}$ cal BP, but until recently, there was little reliable information concerning human occupation during the following period, between 45 and $40 \mathrm{ka}$ cal BP. Here we present results of the excavation of the site of Tolbor-21, in the Selenga drainage system, Northern Mongolia. We focus on Tolbor-21 Archeological Horizon 4 (AH4), an archeological assemblage that documents human occupations that fall stratigraphically and chronologically between the Initial and the Early Upper Paleolithic. We report on the spatial distribution of the finds, the zooarcheological and the lithic data to determine which of the observations reflect post-depositional processes, and which are informative of human behavior. Our initial results presented here show evidence of reworking and preservation bias on a succession of occupations, the exploitation of medium/large herbivores, and a potential structured use of space. At the regional level, our results suggest that improving the resolution of data collection may identify previously undocumented episodes of human occupation. At a broader scale, the Tolbor-21 AH4 assemblage brings new perspectives on the development of the Early Upper Paleolithic in Central and Northeast Asia.

\section{Keywords: Mongolia Initial upper paleolithic Early upper paleolithic Taphonomy Chronology Technological changes}

\section{Introduction}

One of the most extensive archeological records for the beginning of the Upper Paleolithic in Eurasia comes from an under-investigated region, bounded by the Altai Mountains, East Kazakhstan and Dzungaria to the west, and the Yellow River Basin to the east (Derevianko et al., 1993, 2012; Goebel et al., 1993; Derevianko, 2001; Li et al., 2013; Peng et al., 2014). Within this region, two types of assemblages are represented for the beginning of the Upper Paleolithic: the Initial Upper Paleolithic (IUP), which begins as early as 46 ka cal. BP and marks a shift in the regional sequence toward blade-based production, and the Early Upper Paleolithic (EUP), which emerges after $40 \mathrm{ka} \mathrm{cal} \mathrm{BP.}$ Despite some regional variation between western and eastern Eurasia (Kuhn and Zwyns, 2014, 2018; Hoffecker et al., 2019; Kuhn, 2019; Hublin et al., 2020; Fewlass et al., 2020), the IUP is consistent enough in Central and East Asia to be associated with Homo sapiens dispersals along a 'Northern Route' as early as 46-45 ka cal BP (Goebel, 2004, 2015; Zwyns, 2012; Fu et al., 2014; Madsen et al., 2014; Rybin, 2014; Hublin, 2015; Hoffecker, 2017; Li et al., 2019; Izuho et al., 2019; Kadowaki et al., 2019; Zwyns et al., 2019). In addition to specific typological markers (Rybin, 2000, 2014), IUP assemblages often show distinctive technological features that stem from a strong emphasis on the production of blades. Large blade production (Rybin, 2004; Zwyns, 2012; Slavinsky et al., 2016), the recycling of thick technical elements into burin-cores (Zwyns et al., 2012; Slavinsky et al., 2019) and platform preparation by pecking (Slavinsky et al., 2017; Zwyns and Lbova, 2019) are among the most distinctive traits. Notably, the IUP includes the earliest examples of personal ornament and 
formal bone tools (Derevianko and Rybin, 2003; Lbova, 2011). Some authors have considered late examples of the IUP until ca. 30 ka cal BP in the Gobi Altai and the Cis-Baikal region (Derevianko et al., 2004, 2015), but closer to the study area the industry is replaced around 40 ka cal BP by assemblages grouped under the label Early Upper Paleolithic (EUP) (Gladyshev et al., 2010; Rybin et al., 2016). More variable in geographical distribution and assemblage composition, the EUP moves away from a strict focus on large blades to integrate a more specialized production of bladelets (Rybin et al., 2007), a shared pattern globally marking changes in successful hunting weaponry (Teyssandier et al., 2010) and hunter-gatherer patterns of mobility (Bon, 2005). At the regional level, the EUP could be the logical continuation of the IUP (Derevianko et al., 2013), or a rupture in the local sequence consecutive to a population turnover (Zwyns, 2012), but reliable data concerning human occupation during the 45 to 40 ka cal BP time interval is currently lacking. Essentially, we know too little about hunter-gatherer groups during this critical period to properly test models of demography or behavioral adaptation. What were their social structures? What resources, subsistence strategies and settlement patterns did they rely on? While our understanding of the general chrono-cultural framework is quickly improving, obstacles - not least the lack of studies of site formation processes - prevent us from directly addressing these problems. The redeposition of archeological assemblages can leave few clues as to how many people visited the site, how many times and for what purpose (Bertran et al., 2003, 2010; Jaubert et al., 2004; Dibble et al., 2017b). In Northern Mongolia, time-averaging issues (Izuho et al., 2019) are compounded by the problem of preservation bias (i.e. the decay of organic remains). In the Altai and Transbaikal regions (Germonpr?e and Lbova, 1996; Turner et al., 2013; Wrinn, 2010), zooarchaeological studies have brought rare but precious information on site function, subsistence strategies, carnivore activity and seasonality patterns. The poor preservation of bones in open-air sites means that there are only a few such analyses on material of this age (Simonet et al., 2012). Here we present results of excavations at the site of Tolbor-21 (T21), in the Selenga drainage system. We focus on Archeological Horizon 4 (AH4), which documents human occupations around 42-43 ka cal. BP and falls stratigraphically and chronologically between the Initial and the Early Upper Paleolithic. We consider site formation processes with the goal of determining which of the observations reflect postdepositional processes, and which are informative about human behavior. This paper presents an initial investigation of the spatial distribution of the finds, the available zooarcheological and chronological data, and the structure of the lithic assemblage. Overall, AH4 provides a potentially valuable insight into human behavioral adaptations in the region at a time that has not previously been investigated.

\section{Material}

Tolbor-21 $(49.1504700 \mathrm{~N}, 102.5702800 \mathrm{E})$ is in the middle of the valley of the Ikh-Tulberiin-Gol (Great Tolbor River; hereafter, Tolbor), at $1089 \mathrm{~m}$ asl, $12 \mathrm{~km}$ away from the confluence with the Selenga River (Fig. 1). It lies on a fan-shaped slope (14.) formed by polygenetic sediments ca. $500 \mathrm{~m}$ to the west of, and $40 \mathrm{~m}$ above, the current level of the Tolbor. Exposed to the southeast, the site benefits from sunlight during most of the day while staying sheltered from the north wind. The landform sits within a lateral valley adjacent to the main river, and erosional gullies formed during the Holocene mark its limits. A broad viewshed opens on a long section of the Tolbor; outcrops of metamorphic rocks located 100-200 m from the site, and slightly rounded blocks lying along the rills, are local sources of raw material (Fig. 2). The joint expedition of the Institute of Archaeology and Ethnography of SB RAS (Russia), the Institute of Archaeology of the Mongolian Academy of Sciences (Mongolia), and the University of Arizona (USA) discovered the site in 2011. An international team from the Institute of Archaeology of the Mongolian Academy of Sciences (Mongolia), the Institute of Archaeology and Ethnography of SB RAS (Russia), and the University of California (Davis, USA) conducted excavations between 2014 and 2017 under the field direction of E. Rybin, N. Zwyns and B. Tsedendorj. The excavation consists of four pits and two test pits along the slope, at an elevation of ca. 25-28 $\mathrm{m}$ from the bottom of the gully. During survey, archeological material was collected around the whole landform; the goal of the excavation was to test the potential of the site on the upper and lower part of the hill, and in its western and eastern flanks (Fig. 3). The sediments with artifacts at T21 consist of a Holocene soil complex (unit 1), aeolian silt and reworked aeolian silt with gravel (unit 2), and a long sequence of slopewash deposits (unit 3 onward) whose character varies over time and space owing both to extrinsic factors like climate, and to landscape position. The variable character and thickness of these deposits mean that they had to be numbered individually for each pit, but in general they comprise reworked aeolian silt with locally-derived sand, and represent depositional processes too low in energy for the redistribution of artifacts to have taken place (larger clasts within the deposits represent gravitational input from nearby bedrock outcrops). However, multiple episodes of solifluction affect the sediments in on artifact distribution. Ground movements for Pits 1 and 2 are presented in Fig. 4. An episode of solifluction can be seen to affect the deposits housing AH4 in both pits following their deposition (blue lines); following the deposition of $\mathrm{AH} 3$ and some of the overlying sediments, another episode of solifluction takes place (red lines), and the underlying deposits housing AH4 are occasionally caught up in this subsequent movement. Solifluction affects lithological units (LU) 2.2 and 3.1 as well; indeed, the entire landform on which the site sits is built up through a cycle of aeolian deposition and slope wash, interrupted by episodic solifluction, but these solifluction events seldom involve the sediments of more than one or two lithological units, limiting mixing and leaving the stratigraphic succession broadly intact. Pit 1: Located on the Western part of the slope, excavation exposed a $12 \mathrm{~m} 2$ surface between two earlier test pits (Tabarev et al., 2012). The pit is $2.2 \mathrm{~m}$ deep, and an additional $1 \mathrm{~m} 2$ test unit, excavated along the north wall, exposed a further $1 \mathrm{~m}$ depth of sediments below the main artifact concentration. The stratigraphy of the pit is divided into $9 \mathrm{LU}$ that contain $6 \mathrm{AH}$. As described above, the sedimentary sequence at the top of the section comprises a Holocene soil complex (LU1) overlying aeolian silt (LU2), and slope deposits (LU3 onward) subjected to successive episodes of solifluction. Higher-energy slope processes appear to have taken place here than elsewhere on the landform, resulting in the deposition of a few bedded gravels below the main artifact concentration and possibly accounting for the thickness of AH4 (LU4) as a whole; whether the underlying bedded gravels are equivalent to any LU seen elsewhere on the landform, or represent a local sequence, is unclear based on the small area exposed in the test unit (Fig. 5c, Table 1). AHs are not always easy to identify, and they are defined based (by order of importance) on the sedimentary units, the solifluction lobe, the raw material and techno-typological features they display. AHs are distributed between LU1 and LU6; an image combining photogrammetry, lithic projections, and a section drawing for Pit 1 is presented in Fig. 5c. Pit 2: Oriented north-south, the pit exposed a $12 \mathrm{~m} 2$ surface adjacent to an erosional gully at the eastern edge of the site, ca. $30 \mathrm{~m}$ east of Pit 1. The 2016-2017 excavations exposed approximately $1.70 \mathrm{~m}$ of sediments, which, as elsewhere, are subdivided into three major units: the Holocene soil 
(LU1), loess and reworked loess (LU2) and a laminar soliflucted silt with sand, gravel, and cobbles (LU3); stratigraphic subdivisions are described below (Fig. 5a, Table 2). The archaeology is distributed between LU1 and LU3, with LU3 yielding four discernible AHs. An image combining photogrammetry, lithic projections, and a section drawing for Pit 2 is presented in Fig. 5a. Pit 4: This $1.4 \mathrm{~m}$ deep excavation exposed a $12 \mathrm{~m} 2$ surface located on the upper part of the hill slope. Oriented north-south, the excavation is cut in from the side of a recent (Holocene) gully (Fig. 5b, Table 3). As elsewhere, the excavation exposed the Holocene soil sequence (LU1), loess, reworked loess and humic sediments (LU2), and just over a meter of sandy silt with gravel (LU3). This sediment, within which individual units are distinguished based on slight variations in color, texture, and laminarity, houses $\mathrm{AH} 3$ and $\mathrm{AH} 4$ and, like other sections at Tolbor-21, probably comprises several superposed solifluction lobes. An image combining photogrammetry, lithic projections, and a section drawing for Pit 1 is presented in Fig. 5b.

\section{Methods}

Excavation: The excavation was mapped using a total station and the data was collected using EDM-Mobile software (McPherron and Dibble, 2002) (Figs. 5 and 6). All artifacts larger than $20 \mathrm{~mm}$, including bones and specific finds like pieces of ochre, were piece-plotted. Objects with a discernible long axis were plotted in 2 points for analysis of artifact orientation and inclination. We plotted every rock over $250 \mathrm{~mm}$, and the surface of each layer. In a $1 \mathrm{~m}$-grid system, we excavated ca. 30-50 mm thick spits in sub-units of 50 50cm within identifiable sedimentary units, which roughly corresponds to a bucket (8-10 L) of sediments. We plotted every bucket before dry sieving the content with 2 and $4 \mathrm{~mm}$ mesh. The distribution of finds was mapped using New-Plot GIS software (McPherron and Dibble, 2002). Overall, the methods used at T21 are consistent with our previous work in the valley to produce comparable datasets (Zwyns et al., 2014, 2019). Radiocarbon dates: The samples were pretreated at MPI-EVA Leipzig using the method described in Talamo and Richards (2011) (Table 6). Approximately $500 \mathrm{mg}$ of the whole sample were first cleaned and then demineralized in $0.5 \mathrm{M} \mathrm{HCl}$ at room temperature until no $\mathrm{CO}_{2}$ effervescence could be observed. $0.1 \mathrm{M} \mathrm{NaOH}$ was then added for 30 min to remove humics. The $\mathrm{NaOH}$ step was followed by further rinsing with $0.5 \mathrm{M} \mathrm{HCl}$ for $15 \mathrm{~min}$. The sample was then gelatinized, following Longin (1971), in a pH3 solution at $75 \diamond \mathrm{C}$ for $20 \mathrm{~h}$. The resulting gelatin was first filtered in an Eeze-Filter ${ }^{\mathrm{TM}}$ (Elkay Laboratory Products (UK) Ltd.) to remove small (<8 mm) particles and then through a 30 kDa ultrafilter (Sartorius "Vivaspin 15") (Brown et al., 1988). Prior to use, the filter was cleaned to remove carbon-containing humectants (Brock et al., 2007). The sample was then lyophilized for $48 \mathrm{~h}$. Samples were selected for dating when showing a satisfactory amount of collagen yield (>1\%) (Ambrose, 1990; Weber et al., 2005; Hublin et al., 2012) and C:N between 2.9 and 3.5 (Klinken, 1999 ). The selected samples were dated by AMS at the Klaus-Tschira-Labor für Physikalische Altersbestimmung (Curt-Engelhorn-Zentrums für Archaometrie), Mannheim, Germany (Kromer et al., 2013). The results are calibrated in OxCal 4.3 (Bronk-Ramsey, 2009) using the IntCal13 calibration curve (Reimer et al., 2013). Spatial analyses: We used fabric analyses to test for the impact of post-depositional processes on the accumulation and distribution of archeological material. The orientation of particles (rock blocks, artifacts, or bones) is informative about the deposition of the lithological layer and the artifacts (Bertran and Texier, 1995; Lenoble and Bertran, 2004; McPherron, 2005, 2018). Orientation and inclination data were recorded for all finds with a discernible long-axis (e.g. blades or bone fragments) using a total station. Fauna (small sample-size) and unmodified rocks (poorly standardized in size) are not included here. The data were processed following McPherron (2005, 2018). Rose diagrams illustrating the bearing (and Schmidt diagrams showing the inclination) of artifacts were generated in PAST3 software, and Benn diagrams were generated in R (R Core Team, 2018) using the codes provided by McPherron (2018). We use Rayleigh test of uniformity for circular data and T-test to evaluate the impact of site formation processes on artifact bearing and plunge, respectively, with a significance level at 0.01 To identify the clustering of finds, we used Hierarchical Clustering Analysis (HCA) (Kintigh and Ammerman, 1982; Simek and Larick, 1983). We use the results in conjunction with qualitative observations for each excavation pit separately. The analysis included all three coordinates for each lithic artifact (over $2 \mathrm{~cm})(Z$ expansion factor $1 / 4$ depth) (Anderson and Burke, 2008) in order to take into consideration the vertical distribution of artifacts. Agglomerative cluster analysis first places each object into an independent cluster, and the finds are then grouped in an optimal fashion, by calculating the difference between the distance separating the clusters and the number of observations. The squared Euclidean distance is a measure for distance, with possibilities ranging from 2 to 10 . The distance between clusters is the average value of distances between all possible pairs of observations. Zooarchaeological analysis: Bone and bone fragments are identified by species, or by ungulate size classes (Brain, 1981) (Table 4). The anatomical identification followed the "element, portion, segment" system (Gifford and Crader, 1977) and analyses of the bone surfaces were conducted on all the remains. We used a low-angled light and a hand lens (enlargement: 40x) for taphonomic and zooarchaeological observations on bone surfaces. The goal was a systematic search for weathering, root etching, anthropogenic and carnivore modifications (Behrensmeyer, 1978; Olsen and Shipman, 1988; Blumenschine et al., 1996; D'Errico and Villa, 1997; Pickering and Egeland, 2006). The proportion of preserved cortical surface was estimated per quartile (Rendu et al., 2019) and oxide colorations of the bone cortical surfaces were recorded when present. We recorded all human modifications (e.g. cut marks, scraping, notches, cortical notches, percussion marks), distinguishing between notches for food extraction and those from shaping the blanks (the former recognized when in direct relationship with the original splitting of the bone and altering the medullar part of it). Notches are secondary when the notch cut through the main splitting fracture. Because they occur after the original split, secondary notches are interpreted as evidence for shaping of the blank. When necessary, and additional evaluation was conducted using a 20-80x microscope. The nature of the breakage (green, dry and recent) was determined following the criteria defined by Villa and Mahieu (1991) and Gifford-Gonzalez (2018). Lithic analyses: We focus here on the lithic material of $\mathrm{AH} 4$ with standard qualitative and quantitative attributes recorded into a MS Access database using the E4 software (McPherron and Dibble, 2002). We used standard descriptive statistics and $X_{2}$ tests (the significance threshold is 0.05 , and 0.01 after Bonferroni correction) to examine and compare the basic composition of the assemblage between pits. To evaluate whether the whole or just parts of the reduction sequences took place at a given location, we looked at micro-debitage and the frequency of cortex or technical flakes (e.g. crested blades). Tool/blank ratio is used as a measure for the degree of curation of the blanks, while core/blank ratio is used to evaluate the intensity of the core reduction (and how it speaks to potential import/export of material) (Kuhn, 1992, 1996; Li et al., 2016). For calculating the tool/blank ratio, we assigned the status of "blank" to blades, flakes and technical blanks. For calculating the core/blank ratio, we assigned the status of "core" to preforms and cores, while blanks include retouched tools. The sum of formal, informal, and specific tool categories is used as a measure of artifact diversity per assemblage. The 
categories used are in Table 8, in bold characters. Based on ethnographic data, Shott (1986) considers that artifact diversity is informative on the frequency and magnitude of hunter-gatherer group movements. It also provides insight on the spectrum of activities taking place at the site, and potentially on settlement patterns (Binford, 1978, 1980; Vaquero and Romagnoli, 2018). Granted, there is no perfect method to address the issues of curation, mobility, and site function; nevertheless the basic metrics presented here are considered relevant enough to start a discussion (Andrefsky, 2005).

\section{Results}

\subsection{Chronology}

The first direct dates obtained at T21 derive from samples collected by A. Tabarev in Test Pits 1 and 2 (TP1-TP2) (Gladyshev et al., 2013) (Table 6). Due to the lack of stratigraphic information, they are not directly comparable with the dates obtained in other pits. We note, however, that the results are consistent with ages obtained for AH4 in Pit 1, Pit 2 and Pit 4 (95.4\% confidence interval). In Pit 1, the radiocarbon date MAMS-28272 indicates an age between 42.7 and $42.0 \mathrm{ka}$ cal BP for AH4, while AH 5 (N 1/43 3; including roughly processed bifacial tool) includes a bone sample with the MAMS-28273 infinite age. In Pit 2, the AH3 assemblage (Early Upper Paleolithic) is dated by the MAMS-41774 sample or 41.3 to $39.6 \mathrm{ka}$ cal BP. Based on a bone sample (MAMS-31817) collected within CF1 (square unit M11, $20 \mathrm{~cm}$ below the first dark spot, at the level of the second one), AH4 is dated between 42.6 and 41.8 cal BP while two additional dates (MAMS31816, MAMS-31818) confirm an age for the AH4 assemblage between 42.7 and $42 \mathrm{ka}$ calBP. Another bone sample collected below the base of CF1 would provide the only date for AH5 (Initial Upper Paleolithic) between 46.9 and 45.3 ka cal BP (MAMS-31819), or. In Pit 4, two radiocarbon dates are available for AH4.An age between 42.7 and $41.4 \mathrm{ka}$ cal BP (MAMS-41784) is in line with the ages obtained for AH4 elsewhere while a date between 35.3 and 34.4 cal BP (MAMS-41773) is significantly younger. The sample was collected adjacent to a large krotovina an after examination, it was identified as a humeral fragment of Marmota. This genus includes species that are known to live and hibernate in burrows.

\subsection{Spatial distribution of the finds}

Due to sample size constraints, orientation and inclination data groups objects from AH4 found in Pit 1 (N 1/4 27), 2 (N 1/460) and 4 (N $\left.1 \frac{1}{4} 40\right)$. AH2 (Pit 2; N 1/4 37) has a small sample size but is used here as a control sample (Table 7). The results of the Rayleigh and $t$-test (one sample of $\mathrm{AH} 4(\mathrm{~N} 1 / 4126)$ ) indicate bearing and plunge consistent with post-depositional movement ( $\mathrm{p} 1 / 4<0.01)$; artifacts from $\mathrm{AH} 4$ are oriented parallel to dip. The Benn Diagram is consistent with relatively low-energy slope processes including solifluction, which seems to have had a more pronounced impact on artifact distribution in $\mathrm{AH} 4$ than in $\mathrm{AH} 2$ (Fig. 6). When we look at the data for the three different pits, the direction of the bearing appears consistent. It is clearly expressed in Pit 2, while the material from the two other pits falls below the acceptable sample size. In Pit 1, the laminar slope deposits of LU3 and upward contain several identified archeological horizons. LU3 includes two archeological horizons: AH2 (in LU3.1 and 3.2, as well as the overlying unit 2.2), and AH3 (in LU3.3). AH4, which comprises a 35-40 cm-thick deposit of artifacts and bones sits in lithological unit 4 (Fig. 5). A 5-7 cm thick band of sediments with few to no artifacts separates the two horizons. The southern part of the pit shows a higher density of cultural remains in combination with large blocks, although it is worth noting that doubling of the deposits by solifluction is conjectured for the southwest corner (Fig. 4a), which may be responsible for some of this increased density. Cores are concentrated in that area, while blanks (blade fragments, laminar flakes) and the frequency of finds less than $2 \mathrm{~cm}$ in size (e.g. bladelets) increase upslope toward the northwestern corner of the pit (Fig. 7). While the spatial distribution indicates size sorting, low energy run-off on a slope (where lighter objects should move further down the slope relative to heavier ones) does not explain the distribution of heavier and lighter elements. Based on qualitative observation, there is no apparent concentration. HCA suggests that the excavated area divides in two (almost equal) clusters in the north and in the south (Fig. 8), but these results are interpreted as a status quo bounded by the limits of the pit and the dip of the sediments. In Pit 2, four assemblages are distinguished within the laminar slope wash deposits based on stratigraphy, typo-technological criteria and raw material differences: $\mathrm{AH} 2$ (distributed throughout LU3.1 and 3.2 as well as the overlying LU2.2), AH3 (a dense deposit without clear horizontal or vertical spatial distribution, within LU3.3), and AH4, a $0.25-0.3 \mathrm{~m}$ thick horizon within lithological unit 3.4 and separated from the overlying AH by a ca. 5 $\mathrm{cm}$ sterile gap in some areas. AH5 is a small assemblage associated with LU3.6 (Fig. 5). Within AH4, two main concentrations, resulting from post-depositional solifluction ( $\mathrm{AH} 4 \mathrm{a}$ and $\mathrm{b}$ ), are further distinguished from the projections ( $0.5 \mathrm{~m}$ from the wall). AH4a is thicker (10 $\mathrm{cm}$ ) owing to further local doubling during solifluction, but the lithological unit housing the two concentrations is the same, and they represent the doubling of a single occupation horizon (Figs. $4 \mathrm{~b}$ and 5). The elongated lithics and bones found in AH4a are flat-lying and oriented north-south along the current dip, while inclination varies from 0 to 10 relative to the horizontal plane (Fig. 5). In AH4a, the densest concentration of artifacts is in squares L10, M10, and M11. It within the cluster (Figs. 7 and 11); one of which is also a bone accumulation (10 fragments from the area of about $0.2 \mathrm{~m} 2$ ). Two bones out of four feature traces of anthropogenic modification (see below). The highest frequency of cores is in cluster 1 (in the southeastern part of the excavation pit). Clusters 2 and 4 are small, with a few cores and up to $18 \%$ of tools (cluster 2). Two stained sediment spots - CF1 and CF2 - are tentatively interpreted as remains of combustion features (but see below). They lie beneath but in direct connection with AH4a (without sterile layer in between), and are affected by solifluction along with the other sediments. CFs are thin circular red and dark brown finely laminar sandy loam deposits ranging from 50 to $100 \mathrm{~mm}$ thick. Our first observations and the composition of the sediment suggest that it originally corresponded to a single horizon, and that the apparent discontinuity is the result of solifluction. Although labelled here as CF, we consider the alternative possibility of a humic sediment equally plausible, pending the results of additional analyses. CF1 (square units M10, M11) (Fig. 9) includes a large block of heavily gelifracted raw material. Smaller spots have also been observed throughout the adjacent area (square units M10, M11, N10), along with 25 lithic artifacts, including a remarkable combination of two bidirectional cores for blade production in the initial stage of reduction, a large block of raw material, 2 flat bifaces (not found anywhere else at the site), and the largest pointed blade (115 mm long, $37 \mathrm{~mm}$ wide, and $11 \mathrm{~mm}$ thick) found at Tolbor-21. CF2 (Fig. 10) is a spot of ashy and discolored sediment located above the other further down the slope (square unit N12). A hemi-circular line of stones and seven lithic artifacts highlighted it, including two bidirectional cores, a core preform, and an oblique point with proximal thinning. In Pit 4, archeological assemblages occurred in lithological units 1 (AH 1), 2 (AH 2), and 3 ( $A H 3, A H 4$, and $A H 5$, sparsely attested at the base of the section). Unlike the rest of the site, $A H 1-3$ contained an extremely low 
concentration of artifacts - not more than 50 pieces from the entire excavation area. AH4 ranged from 10 to $40 \mathrm{~cm}$ thick and was within LU3.3; although the section is transversal, some distortion (and possible doubling) of AH4 by solifluction is apparent (Fig. 5). In plan, two large stones, around which smaller stones and slabs were concentrated, form a small rectangular structure measuring $1 \geqslant 0.8 \mathrm{~m}$ (square unit D2) (Figs. 7 and 11). An arc of stones placed 0.2-0.3 $\mathrm{m}$ from each other and measuring about $3 \mathrm{~m}$ in length, ran in an east-west alignment. In total, there were 57 stones of different sizes in the structure, including five large boulders (0.3-0.4 $\mathrm{m}$ along the long axis). Two courses of stone slabs and boulders lay upon each other, with significantly fewer stones in the middle, with a dense concentration of stone artifacts and many crushed bones under and over the stones. The largest accumulation of artifacts was in the southwestern corner of the excavation pit (square F3). Another accumulation (square unit D2) adjoined the northern edge of the small structure and partially covered it. A set of four preforms and five cores (half of the eighteen cores found in pit 4) were found tightly concentrated in an area of $0.5 \mathrm{~m} 2$. The assemblage found within the 'structure' included 219 artifacts. Located on the steepest part of the slope close to the erosion cut, the cultural material shows a relatively high isotropy (0.14) (Fig. 6). After analyzing the distribution of artifacts in the stone structure, cluster analysis has shown the optimal 4-cluster solution (Fig. 8). Cluster 1 was highest on the slope and partially covered clusters 2 and 3. In this area, artifact frequency (including those found in the screens) was two times higher than in the rest of the excavation pit. In addition, more than half of the lithic artifacts were blade and flake blanks. Cluster 2 was adjacent to the stone structure in square D2. The large stones may have protected this area from slopewash, and the assemblage is characterized by the balanced frequencies of tools and core-like forms (12\% each), and the presence of large bone fragments with anthropogenic modifications (N 1/4 3). Cluster 3 contained relatively many small fragments of bones. Cluster 4 includes finds partly covered by cluster 3 , thereby indicating possible folding or a succession of 2 occupations. Fabric analysis suggests that the material of these two clusters is redeposited. At the southeastern edge of the excavation pit, the layer eroded, perhaps during the formation of the rill; along with the presence of vertically oriented artifacts, the density of piece-plotted artifacts from sieving markedly decreases (square unit C2, C3, and partially D3).

\subsection{Fauna}

In Pit 1, a tooth fragment from an extinct horse and pika (Ochotona) bone are part of the fragmented assemblage, which also includes a single ostrich (Struthio) eggshell fragment. The minimum number of individuals for all species does not exceed one animal (Table 4). In Pit 2 , the three identified species of ungulates associated with AH3B are extinct horse, wild ass, and Baikal yak (one individual of each species). Remains of a large bovid (probably also a yak) are tentatively identified. The high frequency of unidentifiable fragments (81.7\%) and the evidence for anthropogenic modifications (impact) are consistent with food waste. Notable are the well-represented (50\%) longitudinal bone fragments. Near CF1, three fragments of ostrich eggshell are associated with bones showing evidence of anthropogenic activities. There are only small fragments of bone associated with CF 2 . In addition to individual bones of a rodent, horse and the remains of large and medium ungulates found in Pit 4, the presence of woolly rhinoceros is established based on a tooth fragment. The remains of the Equidae teeth are very fragmented and do not allow for species determination. The degree of bone fragmentation is very high, and only $18.6 \%$ of bones were identifiable. About half of the bones from large animals are split longitudinally, including a single fragment of horse metapodium. There is a single fragment of ostrich eggshell in Pit 4, and all bones with anthropogenic modifications (and most of the small bone fragments) are found near the stone 'structure'. Weathering is very frequent on the material with $60 \%$ of the Number of Remains (NR) (Fig. 12). The frequency of cracking ( $26 \%$ of NR) and exfoliation ( $42 \%$ of NR) are consistent with a slow embedding of the bone assemblage. This finds an interesting echo in the high impact of the root etching observable on activity. In consequence, most of the cortical surface of bones is usually destroyed; indeed, $52 \%$ of the remains have lost more than $75 \%$ of their cortical surfaces. This alone makes it nearly impossible to identify carnivore or human modifications. This said, we observed no carnivore marks, but despite the poor preservation, 11 remains exhibit clear evidence for anthropogenic activities. One cut mark was observed on a rib of a medium size ungulate testifying to meat filleting while two others (additional to the above-mentioned 11 remains) have been observed on two shaft fragments of horse tibia. The most common marks are the notches testifying to marrow and grease recovery ( 3 horse metapodials from Pit 4; 2 horse tibia and 4 large-ungulate shaft fragments from Pit 2 and Pit 4). In addition, a bone flake (Pit 2) also represents bone breakage. Based on these marks, we can assume that the bone assemblage is mostly linked with human activities, such as in situ exploitation of horse carcasses for meat, marrow, and grease.

\subsection{Lithic assemblage}

Blade technology is a part of AH4 in all pits, with blade frequencies varying between 28 and 34\% of the sets (Table 5) (Figss. 13-14). Bladelets also occur in every pit, with frequencies up to $14 \%$. Considered together, laminar elements represent almost half of the material with a frequency equivalent to flakes. The number of retouched tools on blade and flake blanks are relatively comparable, although it is noted that retouched bladelets are rare. When tool frequencies are calculated only with piece plotted artifacts, variation constrained between 10 and $15 \%$ is not significant $\left(X_{2}\left(2, N \frac{1}{4} 1793\right) \frac{1}{4} 4.143, \mathrm{p} 1 / 40.10\right)$. When adding the screened material (counted here as

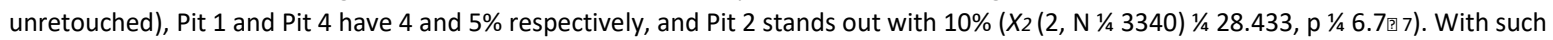
large sample size, the sensitivity of the $X_{2}$ test increases, but the differences also reflect the amount of screened material uncovered peer pit. This is far less abundant in Pit 2 than in Pits 1 and $4\left(X_{2}\left(2, N \frac{1}{4} 3340\right)\right.$ 1/4 294.101, p 1/4 0). There is about 1 tool per $6-10$ blanks, and the difference between pits is not significant $\left(X_{2}(2, N 1 / 41709) 1 / 44.355, p \frac{1}{4} 0.10\right)$. The number of dorsal faces with $10 \%$ or more of their surface covered by cortex is very similar between pits and represents a third of each assemblage. The blank/core ratio (calculated here with blade and flakes included, with the preforms and without the pebbles) show little variations, with values from 20 to 16 ( $X_{2}$ ( $2, \mathrm{~N} 1 / 4$ 1791) $1 / 4$ 1.485, p 1 1 0.48). The tool type diversity (Tables 8 and 9) is higher in Pit 2 and may correlate with the tool frequency. Notable is that about half of the tools in Pit 1 are informal tool-types. With most categories of technical flakes represented in each excavated area, it is reasonable to consider that blank production occurred on site. Core preforms, crested blades, core tablets and unretouched blanks occur in the three pits (Table 5); while one blank out of three still bear cortex. All blank categories (flakes, blades and bladelets) - were retouched, although bladelets much less so. Overall, tool typology and micro-debitage are the most sensitive indicator of variations between the pits. 


\section{Discussion}

The landform on which T21 sits is depositionally complex, such that the AHs have been subjected to several post-depositional sedimentary processes of varying intensity. It is built of a long $(>4 \mathrm{~m})$ sequence of continually accreting low- to moderate-energy slope deposits, at the top of which sit the lithological units housing AH6-2. The accumulation of this sequence resulted from climatically driven cyclic alternation between the deposition of laminar silts (aeolian deposition, pedogenesis, colluviation in the broad sense, and episodic carbonate surface crust formation, with occasional higher-energy episodes), and the slight downslope displacement of packs of these sediments by solifluction, reflecting a meta-stable climatic regime which existed throughout MIS3 and probably earlier (pending dates for the base of the sequence). On the timescale of individual LUs, the accumulation of the laminar silt seems to have been slow and episodic, dominated by low-energy processes primarily affecting particles less than $2 \mathrm{~mm}$ in size. The role of water in depositing the sediments is counterbalanced by evidence for aridity including the precipitation of the thin carbonate crusts that give a laminar appearance to many of the sediments described here. In this setting, humans occupied the site repeatedly during MIS3 and MIS2. This study has focused on AH4, a highly visible occupation around 43-42 ka with a layer saturated in lithic material, a few bones, and some shows variations in the frequency of lithic material, as a whole and between analytical categories. Of the sedimentary processes affecting the deposit, solifluction is the most significant in terms of artifact displacement, most of which would have been lateral (slope wash at the site affects particles less than $2 \mathrm{~mm}$ in size, and is unlikely to have moved larger objects). Vertical displacement is limited to the risers of solifluction lobes, although doubling of the sediments can superpose artifacts that originally lay side by side. The vertical distribution of artifacts, which is mostly original, their situation within episodically accumulating fine-grained sediments, and the overall thickness of the layer (generally on the order of $30 \mathrm{~cm}$ except where doubling has taken place), are most consistent with multiple reoccupations of the site over a long time span rather than reworking of a single, more intense occupation. Despite changes to artifact density resulting from lateral displacements, inferences can still be made about human activity and site formation processes. HCA illustrates two sedimentary processes that have affected the anthropogenic deposits in different ways: inter- and intra-pit variation in the rate of accumulation of the laminar sediment, and solifluction. In the first case, the original clustering of artifacts is obscured by a palimpsest effect in areas with lower sedimentation rates, as might have been the case at the base of LU4 in Pit 1, where HCA (Fig. 8) failed to find meaningful clusters. In the second case, the original distribution of artifacts is distorted by their having flowed, as at Pit 4, where the clusters identified by HCA dominantly reflect the influence of solifluction (lobate forms are visible both in plan (Fig. 7) and in the results of HCA (Fig. 8). If indeed AH4 accumulated gradually through repeated occupations, it is probably wrong to treat it as a single occupation surface, except in the broadest possible sense. The thickness of sediment being considered in cluster analysis makes it difficult to know where clusters might be representative of spatially patterned behavior during a single episode of human activity at the site. Overall, though, HCA identifies several of what appear to be meaningful clusters confirmed by variation in content (lithics and bone). AH4 is likely the result of the long duration of overall use of the hillside, leading to a palimpsest effect, combined with post-depositional sediment movements, which result in slight - mainly lateral changes in artifact position (Fig. 5). Detailed investigation of the faunal remains from AH4 suggests a relatively long surface exposure in contact with vegetation. The resulting taphonomic bias may account for the lack of evidence for carnivore activity; human modifications are important enough within the faunal record, though, to survive this biasing effect. These include butchery of partial carcasses and marrow or grease extraction. The genera and species identified include medium-large grazers typical of open environments. The AH4 lithic assemblages have the blade component in common, but we note a high frequency of retouched flakes and the occurrence of bladelet technology. The results of the analyses are consistent with blade production on site, perhaps taking advantage of local material sources, but in a residential mobility pattern model, mapping on resources would predict a more expedient/poorly curated assemblage than what we observe (Binford, 1978, 1980; Vaquero and Romagnoli, 2018). In AH4, a relatively high raw material quality and quantity coexist with formal and informal tools/core reduction method. Following Shott (1986), the high diversity of tool types (e.g. Pit 2) suggests a low frequency and high magnitude of movements. In the context of the depositional (and perhaps occupational) palimpsest, some of the contradictions could be explained by a time-averaging situation (Bailey, 2007; Perreault, 2018; Izuho et al., 2019). Looking forward, a comparative analysis on the details of the lithic assemblage should clarify the possible connection with the IUP and/or the EUP while investigations on the mobility of hunter-gatherers should help understanding a technological shift recorded affecting a large geographical area. The low-energy nature of the post-depositional processes affecting the archeological deposits means that aspects of the site's original spatial organization may be still visible. This paper has presented evidence of non-random distribution of objects - namely groups of cores, tools and blanks - in different areas. The unequal distribution of micro-debitage may reflect taphonomy (e.g. Pit 2), but in some cases (Pit 1) it is difficult to explain by size-sorting alone (Bertran et al., 2012). More parsimonious is that small-size particles occur in higher frequency upslope because of knapping activities, implying a relatively structured use of space. Given the likelihood of an occupational palimpsest, further analysis may distinguish between artifact groupings resulting from a single activity and those which reflect recurrent or time-stable differentiation of different areas of the site. Unlike the Trans Baikal region (Konstantinov, 1994; Lbova, 2000; Derevianko et al., 2005; Tashak, 2005; Vasiliev and Rybin, 2009; Izuho et al., 2019), the UP in Mongolia so far lacks clear evidence of constructed hearths, storage pits, and stone structures. At T21, AH4 includes potential combustion features and semi-circular stone 'structures'. Because solifluction is documented, though, such features must be interpreted with caution, particularly given their form in plan. Identifying anthropogenic fire is particularly important for the functional interpretation of the site, but field observation is not sufficient for a positive identification (Aldeias, 2017; Dibble et al., 2017a, 2018; Goldberg et al., 2017; Mallol and Henry, 2017); sediments from the potential combustion feature in Pit 2 are currently awaiting further analysis.

\section{Conclusion}

The occupation that resulted in the deposition of AH4 at T21 took place between the IUP (sensu stricto) and the EUP and confirms the presence of humans in the region at this time. The exploitation of medium/large herbivores confirmed by faunal analyses is typical of open landscapes. Our initial results illustrate the impact of reworking and preservation bias on the spatial distribution of artifacts. We also note that taphonomic processes do not explain all observations and may overprint evidence for a structured use of space. Without refits, and 
given the faunal preservation, it is still unclear whether the site corresponds to a large base camp, a succession of small occupations, or both, but geological, lithic data and bone surface alteration suggest that a palimpsest of short occupations is a viable hypothesis.

\section{Declaration of competing interest}

The authors declare that they have no known competing financial interests or personal relationships that could have appeared to influence the work reported in this paper.

\section{Acknowledgments}

The authors are grateful to the Mongol authorities and the Governor of Bulgan Aimag, and to the (many) participants to the field seasons, the staff and the interns who helped us along the way. A special thanks to Aurora Allshouse, Anton Anoikin, Roshanne Bakhtiary, Tamara Dogand zi cis Jovan Galfi, Giulia Gallo, Angaragdulguun Gantumur, Jean- Jacques Hublin, Vladimir Kharevich, Tim Libois, Camille Lesage, Ganbold Margad-Erdene, Masha Medovikova, Josh Noyer, Galina Pavlenok, Kevin Smith, Peiqi Zhang, for their help in the field and in the lab and to Brent Woodfill for use of drone equipment to map the site. We appreciate John W. Olsen, Andrei V. Tabarev and Sergei A. Gladyshev for their help to set up our work in Tolbor valley. The Russian Scientific Foundation supports ER, AMK, DM and AK for lithic (project \#19-18-00198) and faunal (project\# 19-78-10112) analyses. The National Scientific Foundation (\#1560784) supports NZ field research in the Ikh-Tulberiin-Gol. NZ is grateful for the support of the Leakey Foundation, the Max Planck Society, the UC-Davis Department of Anthropology and the UC-Davis Academic Senate, and the Hellman Foundation. S.T. is funded by the European Research Council under the European Union's Horizon 2020 Research and Innovation Programme (grant agreement No. 803147 RESOLUTION, https://site.unibo.it/resoluti on-erc/en).

References Aldeias, V., 2017. Experimental approaches to archaeological fire features and their behavioral relevance. Curr. Anthropol. 58 (S16), S191-S205.

Ambrose, S.H., 1990. Preparation and characterization of bone and tooth collagen for isotopic analysis. J. Archaeol. Sci. 17, 431-451.

Anderson, K.L., Burke, A., 2008. Refining the definition of cultural levels at Karabi Tamchin: a quantitative approach to vertical intra-site spatial analysis. J. Archaeol. Sci. 35, 2274-2285. Andrefsky, W., 2005. Lithics: Macroscopic Approaches to Analysis. Cambridge University Press.

Bailey, G., 2007. Time perspectives, palimpsests and the archaeology of time. J. Anthropol. Archaeol. 26, 198-223.

Behrensmeyer, A.K., 1978. Taphonomic and secologie information from bone weathering. Paleobiology 4, 150-162.

Bertran, P., Texier, J.P., 1995. Fabric analysis: application to paleolithic sites. J. Archaeol. Sci. 22, 521-535.

Bertran, P., Fontugne, M., Jaubert, J., 2003. Permafrost aggradation followed by brutal degradation during the upper pleniglacial in Mongolia: the probable response to the H2 Heinrich event at $21 \mathrm{kyr}$ BP. Permafr. Periglac. Process. 14, 1-9.

Bertran, P., Klaric, L., Lenoble, A., Masson, B., Vallin, L., 2010. The impact of periglacial processes on Palaeolithic sites: the case of sorted patterned grounds. Quat. Int. 214, 17-29.

Bertran, P., Lenoble, A., Todisco, D., Desrosiers, P.M., Sørensen, M., 2012. Particle size distribution of lithic assemblages and taphonomy of Palaeolithic sites. J. Archaeol. Sci. 39, 31483166 .

Binford, L., 1978. Nunamiut: Ethnoarchaeology. Academic Press, New York, 1978.

Binford, L.R., 1980. Willow smoke and dogs' tails: hunter-gatherer settlement systems and archaeological site formation. Am. Antiq. 45, 4-20.

Blumenschine, R., Marean, C.W., Capaldo, S.D., 1996. Blind tests of inter-analyst correspondence and accuracy in the identification of cut marks, percussion marks, and carnivore tooth marks on bone surfaces. J. Archaeol. Sci. 23, 493-507.

Bon, F., 2005. Little big tool. Enqu^ete autour du succ es de la lamelle. In: Productions Lamellaires Attribu ees a l'Aurignacien: Chaines Op eratoires et Perspectives Technoculturelles XIVeme congr es de l'UISPP, Lißege 2-8 Septembre. MNHA, Luxembourg, pp. 479-484.

Brain, C., 1981. The Hunters or the Hunted? an Introduction to African Cave Taphonomy. Chicago-London.

Brock, F., Bronk Ramsey, C., Higham, T., 2007. Quality assurance of ultrafiltered bone dating. Radiocarbon 49, 187-192. Bronk Ramsey, C., 2009. Bayesian analysis of radiocarbon dates. Radiocarbon 51 (1), 337-360.

Brown, T.A., Nelson, D.E., Vogel, J.S., Southon, J.R., 1988. Improved collagen extraction by modified Longin method. Radiocarbon 30, 171-177.

D'Errico, F., Villa, P., 1997. Holes and grooves: the contribution of microscopy and taphonomy to the problem of art origins. J. Hum. Evol. 33, 1-31.

Derevianko, A., Xing, G., Olsen, J., Rybin, E., 2012. The Paleolithic of Dzungaria (Xinjiang, northwest China) based on materials from the Luotuoshi site. Archaeol. Ethnol. Anthropol. Eurasia 40, 2-18.

Derevianko, A.P., 2001. The middle to upper paleolithic transition in the Altai (Mongolia and siberia). Archaeol. Ethnol. Anthropol. Eurasia 2, 70-103.

Derevianko, A.P., Rybin, E.P., 2003. The earliest representations of symbolic behaviour by Paleolithic humans in the Altai Mountains. Archaeol. Ethnol. Anthropol. Eurasia 4, 27-50.

Derevianko, A.P., Nikolayev, S.V., Petrin, V.T., 1993. The dating of the paleolithic kara-bom site with physical methods (C14 and EPR).

Altaica 2-8. Derevianko, A.P., Brantingham, P.J., Olsen, J.W., Tseveendorj, D., 2004. Initial upper paleolithic blade industries from the North-central Gobi desert, Mongolia. In: The Early Upper Paleolithic beyond Western Europe, pp. 207-222. 
Derevianko, A.P., Postnov, A.V., Rybin, E.P., Kuzmin, Y.V., Keates, S.G., 2005. The Pleistocene peopling of Siberia: a review of environmental and behavioral aspects. Bull. Indo Pac. Prehist. Assoc. 25, 57-68.

Derevianko, A.P., Rybin, E.P., Gladyshev, S.A., Gunchinsuren, B., Tsybankov, A.A., Olsen, J.W., 2013. Early Upper Paleolithic stone tool technologies of northern Mongolia: the case of Tolbor-4 and Ttolbor-15. Archaeol. Ethnol. Anthropol. Eurasia 41, 21-37.

Derevianko, A.P., Markin, S.V., Gladyshev, S.A., Olsen, J.W., 2015. The early upper paleolithic of the Gobi Altai region in Mongolia (based on materials from the chikhen-2 site). Archaeol. Ethnol. Anthropol. Eurasia 43, 17-41.

Dibble, H.L., Abodolahzadeh, A., Aldeias, V., Goldberg, P., McPherron, S.P., Sandgathe, D.M., 2017a. How did hominins adapt to ice age europe without fire? Curr. Anthropol. 58 (S16), S278-S287.

Dibble, H.L., Holdaway, S.J., Lin, S.C., Braun, D.R., Douglass, M.J., lovita, R., McPherron, S.P., Olszewski, D.I, Sandgathe, D., 2017b. Major fallacies surrounding stone artifacts and assemblages. J. Archaeol. Method Theor 24 (3), 813-851.

Dibble, H.L., Sandgathe, D., Goldberg, P., McPherron, S., Aldeias, V., 2018. Were western European neandertals able to make fire? J. Paleol.Archaeol. 1, 54-79.

Fewlass, H., Talamo, S., Wacker, L., Kromer, B., Tuna, T., Fagault, Y., Bard, E., McPherron, S.P., Aldeias, V., Maria, R., Martisius, N.L., Paskulin, L., Rezek, Z., Sinet- Mathiot, V., Sirakova, S., Smith, G.M., Spasov, R., Welker, F., Sirakov, N., Tsanova, T., Hublin, J.-J., 2020. A 14 C chronology for the middle to upper palaeolithic transition at bacho kiro cave, Bulgaria. Nat. Ecol. Evol. 1-8.

Fu, Q., Li, H., Moorjani, P., Jay, F., Slepchenko, S.M., Bondarev, A.A., Johnson, P.L.F., Aximu-Petri, A., Prüfer, K., De Filippo, C., Meyer, M., Zwyns, N., Salazar-García, D. C., Kuzmin, Y.V. Keates, S.G., Kosintsev, P.A., Razhev, D.I., Richards, M.P., Peristov, N.V., Lachmann, M., Douka, K., Higham, T.F.G., Slatkin, M., Hublin, J.-J., Reich, D., Kelso, J., Viola, T.B., P€a€abo, S., 2014. Genome sequence of a 45,000 -year-old modern human from western Siberia. Nature 514. Germonpr e, M., Lbova, L., 1996. Mammalian remains from the upper palaeolithic site of Kamenka, Buryatia (Siberia). J. Archaeol. Sci. 23, 35-57.

Gifford-Gonzalez, D., 2018. An Introduction to Zooarchaeology, an Introduction to Zooarchaeology. Springer International Publishing. Gifford, D.P., Crader, D.C., 1977. A computer coding system for archaeological faunal remains. Am. Antiq. 42, 225-238.

Gladyshev, S.A., Olsen, J.W., Tabarev, A.V., Kuzmin, Y.V., 2010. Chronology and periodization of Upper paleolithic sites in Mongolia. Archaeol. Ethnol. Anthropol. Eurasia 38, 33-40.

Gladyshev, G., Jull, A.J.T., Dogandzic, T., Zwyns, N., Olsen, J.W., Richards, M.P., Tabarev, A.V., Talamo, S., 2013. Radiocarbon dating of paleolithic sites in the ikh-tulberiin-gol river valley, northern Mongolia. Vestnik $12(5), 44-48$.

Goebel, T., 2004. The Early Upper Paleolithic of Siberia. The Early Upper Paleolithic beyond Western Europe, pp. 162-195. Goebel, T., 2015. The overland dispersal of modern humans to eastern Asia: an alternative, northern route from Africa. In: Kaifu, Y., Izuho, M., Goebel, T. (Eds.), Emergence and Diversity of Modern Human Behavior in Paleolithic, pp. 437-452.

Goebel, T., Derevianko, A.P., Petrin, V.T., 1993. Dating the middle-to-upper-paleolithic transition at Kara-Bom. Curr. Anthropol. 34, 452. Goldberg, P., Miller, C.E., Mentzer, S.M., 2017. Recognizing fire in the paleolithic archaeological record. Curr. Anthropol. 58, S175-S190.

Hoffecker, J., 2017. Modern Humans: Their African Origin and Global Dispersal. Columbia University Press.

Hoffecker, J.F., Holliday, V.T., Nehoroshev, P., Vishnyatsky, L., Otcherednoy, A., Salnaya, N., Goldberg, P., Southon, J., Lehman, S.J., Cappa, P.J., Giaccio, B., Forman, S.L., Quade, J., 2019. The dating of a middle paleolithic blade industry in southern Russia and its relationship to the initial upper paleolithic. J. Paleol. Archaeol. 2 (4), 381-417.

Hublin, J.-J., Talamo, S., Julien, M., David, F., Connet, N., Bodu, P., Vandermeersch, B., Richards, M.P., 2012. Radiocarbon dates from the grotte du Renne and saint-cesaire support a neandertal origin for the chatelperronian. Proc. Natl. Acad. Sci. Unit. States Am. 109 (46), 18743-18748.

Hublin, J.J., 2015. The modern human colonization of western Eurasia: when and where? Quat. Sci. Rev. 118, 194-210.

Hublin, J.J., Sirakov, N., Aldeias, V., Bailey, S., Bard, E., Delvigne, V., Endarova, E., Fagault, Y., Fewlass, H., Hajdinjak, M., Kromer, B., Krumov, I., Marreiros, J., Martisius, N.L., Paskulin, L., Sinet-Mathiot, V., Meyer, M., P€a€abo, S., Popov, V., Rezek, Z., Sirakova, S., Skinner, M.M., Smith, G.M., Spasov, R., Talamo, S., Tuna, T., Wacker, L., Welker, F., Wilcke, A., Zahariev, N., McPherron, S.P., Tsanova, T., 2020. Initial upper palaeolithic Homo sapiens from bacho kiro cave, Bulgaria. Nature 581, 299-302.

Izuho, M., Terry, K., Vasil'ev, S., Konstantinov, M., Takahashi, K., 2019. Tolbaga revisited: scrutinizing occupation duration and its relationship with the faunal landscape during MIS 3 and MIS 2. Archaeol. Res. Asia 17, 9-23.

Jaubert, J., Bertran, P., Fontugne, M., Jarry, M., Lacombe, S., Leroyer, C., Marmet, E., Taborin, Y., Tsogtbaatar, B., Others, 2004. Le Pal eolithique superieur ancien de Mongolie: DEorEolj 1 (Egiin Gol). Analogies avec les donn ees de l'Altai et de Sib erie. In: The Upper Palaeolithic General Sessions and Posters. Acts of the XIVth UISPP Congress. University of Liege, Belgium, p. 245, 2-8 September.

Kadowaki, S., Tamura, T., Sano, K., Kurozumi, T., Maher, L.A., Wakano, J.Y., Omori, T., Kida, R., Hirose, M., Massadeh, S., Henry, D.O., 2019. Lithic technology, chronology, and marine shells from Wadi Aghar, southern Jordan, and Initial Upper Paleolithic behaviors in the southern inland Levant. J. Hum. Evol. 135, 102646.

Kintigh, K.W., Ammerman, A.J., 1982. Heuristic approaches to spatial analysis in archaeology. Am. Antiq. 47, 31-63.

Klinken, G.J. Van, 1999. Bone collagen quality indicators for palaeodietary and radiocarbon measurements. J. Archaeol. Sci. 26, 687-695.

Konstantinov, M., 1994. The Stone Age of the Eastern Part of Baikal. Chita State Pedagogical Institute, Chita.

Kromer, B., Lindauer, S., Synal, H.A., Wacker, L., 2013. MAMS - a new AMS facility at the curt-engelhorn-centre for achaeometry, Mannheim, Germany. In: Nuclear Instruments and Methods in Physics Research, Section B: Beam Interactions with Materials and Atoms, pp. 11-13.

Kuhn, S., Zwyns, N., 2018. Convergence and continuity in the initial upper Paleolithic of Eurasia. In: O'Brien, M.J., Buchanan, B., Ehren, M. (Eds.), Convergent Evolution in Stone-Tool Technology. The MIT Press, pp. 132-152

Kuhn, S.L., 1992. On planning and curated technologies in the middle paleolithic. J. Anthropol. Res. 48, 185-214. Kuhn, S.L., 1996. Mousterian Lithic Technology: an Ecological Perspective. Princeton University Press.

Kuhn, S.L., 2019. Initial Upper Paleolithic: a (near) global problem and a global opportunity. Archaeol. Res. Asia 17, 2-8. Kuhn, S.L.,

Zwyns, N., 2014. Rethinking the initial upper paleolithic. Quat. Int. 347, 29-38.

Lbova, L., 2011. Evidence of modern human behavior in the baikal zone during the early upper paleolithic period. Bull. Indo Pac. Prehist. Assoc. 30, 9-13.

Lbova, L.V., 2000. Palcolit Severnoi Zony Zapadnogo Zabaikalia (Palaeolithic of the North-Western Part of Transbaikalia). Ulan-Ude: Izd. BNC SO RAN, Ulan-Ude. 
Lenoble, A., Bertran, P., 2004. Fabric of Palaeolithic levels: methods and implications for site formation processes. J. Archaeol. Sci. 31, 457-469. Li, F., Kuhn, S.L., Gao, X., Chen, F. you, 2013. Re-examination of the dates of large blade technology in China: a comparison of Shuidonggou Locality 1 and Locality 2. J. Hum. Evol. 64, 161-168

Li, F., Kuhn, S.L., Chen, F. you, Gao, X., 2016. Raw material economies and mobility patterns in the Late Paleolithic at Shuidonggou locality 2, north China. J. Anthropol. Archaeol. 43, 8393.

Li, F., Vanwezer, N., Boivin, N., Gao, X., Ott, F., Petraglia, M., Roberts, P., 2019. Heading north: late Pleistocene environments and human dispersals in central and eastern Asia. PLoS One $14, \mathrm{e} 0216433$.

Longin, R., 1971. New method of collagen extraction for radiocarbon dating. Nature 230, 241-242.

Madsen, D.B., Oviatt, C.G., Zhu, Y., Brantingham, P.J., Elston, R.G., Chen, F., Bettinger, R.L., Rhode, D., 2014. The early appearance of Shuidonggou core-and-blade technology in north China: implications for the spread of Anatomically Modern Humans in northeast Asia? Quat. Int. 347, 21-28.

Mallol, C., Henry, A., 2017. Ethnoarchaeology of paleolithic fire: methodological considerations. Curr. Anthropol. 58, S217-S229. McPherron, S.J.P., 2005. Artifact orientations and site formation processes from total station proveniences. J. Archaeol. Sci. 32, 1003-1014.

McPherron, S.P., 2018. Additional statistical and graphical methods for analyzing site formation processes using artifact orientations. PLoS One 13, 1.

McPherron, S.P., Dibble, H.L., 2002. Using Computers in Archaeology: a Practical Guide. McGraw-Hill/Mayfield.

Olsen, S.L., Shipman, P., 1988. Surface modification on bone: trampling versus butchery. J. Archaeol. Sci. 15, 535-553. PAST3. https://folk.uio.no/ohammer/past/.

Peng, F., Wang, H., Gao, X., 2014. Blade production of shuidonggou Locality1 (northwest China): atechnological perspective. Quat. Int. 347, 12-20.

Perreault, C., 2018. Time-averaging slows down rates of change in the archaeological record. J. Archaeol. Method Theor 25, 953-964.

Pickering, T.R., Egeland, C.P., 2006. Experimental patterns of hammerstone percussion damage on bones: implications for inferences of carcass processing by humans. J. Archaeol. Sci. 33, 459-469. R Core Team, 2018. R: A Language and Environment for Statistical Computing. R Foundation for Statistical Computing, Vienna, Austria. URL. https://www.Rproject. org/.

Reimer, P.J., Bard, E., Bayliss, A., Beck, J.W., Blackwell, P.G., Ramsey, C.B., Buck, C.E., Cheng, H., Edwards, R.L., Friedrich, M., Grootes, P.M., 2013 . IntCal13 and Marine13 radiocarbon age calibration curves 0-50,000 years cal BP. Radiocarbon 55 (4), 1869-1887.

Rendu, W., Renou, S., Soulier, M.-C., Rigaud, S., Roussel, M., Soressi, M., 2019. Subsistence strategy changes during the Middle to Upper Paleolithic transition reveals specific adaptations of Human Populations to their environment. Sci. Rep. 9, 15817.

Rybin, E., 2004. Middle paleolithic" blade" industries and the middle-to-upper-paleolithic transition in south siberia: migration or regional continuity? BAR Int. Ser. 1239, 81-90.

Rybin, E.P., 2000. K voprosu o "rykovodyatsik ickopaemiikh" v industrialniikh komplekcakh rannei porii verknego paleolita gornogo Altaya. (About specific lithic tools in the Early Upper Paleolithic assemblages of Russian Altai). In: Paleogeografiya Kamennogo Veka. Korreltisya Prirodniik Cobotii I Arkheologicheskiik Kultur Paleolita Severnoy Azii in Sopredelniik Territorii: Materialii Mejdunarodnoi Konferentsiii. Krasnoyarsk, pp. 123-126.

Rybin, E.P., 2014. Tools, beads, and migrations: specific cultural traits in the initial upper paleolithic of southern siberia and central Asia. Quat. Int. 347, $39-52$.

Rybin, E.P., Gladyshev, S.A., Tsybankov, A.A., 2007. Vozniknovenje i razvitie "otsepovikh" industrii rannei porii verknego paleolita cevernoi Mongolia (Emergence and development of another Early Upper Paleolithic industry in Northern Mongolia). In: Severnaya Evrasia V Anthropologenie. Chelovek Paleolitechnologii, Geoecologia, Ethnografii I Anthropologii, pp. 137152.

Rybin, E.P., Khatsenovich, A.M., Gunchinsuren, B., Olsen, J.W., Zwyns, N., 2016. The impact of the LGM on the development of the Upper Paleolithic in Mongolia. Quat. Int. 425, 69-87.

Shott, M.J., 1986. Settlement mobility and technological organization: an ethnographic examination. J. Anthropol. Res. 42, 15-51.

Simek, J.F., Larick, R.R., 1983. The recognition of multiple spatial patterns: a case study from the French upper paleolithic. J. Archaeol. Sci. 10, 165-180.

Simonet, A., Tseveendorj, D., Goutas, N., Magail, J., 2012. Tsatsyn Ereg 2: campagne 2012 de la mission archeologique Monaco-Mongolie. Bull. Musee Anthropol. Prehist. Monaco 52, $113-125$.

Slavinsky, V.S., Rybin, E.P., Belousova, N.E., 2016. Variation in the middle and upper paleolithic reduction technology at kara-bom, the Altai Mountains. Archaeol. Ethnol. Anthropol. Eurasia 44, 39-50.

Slavinsky, V.S., Rybin, E.P., Belousova, N.E., Fedorchenko, A.Y., Khatsenovich, A.M., Anoikin, A.A., 2017. Specific technique of core platform preparation in the initial upper paleolithic of south siberia and central Asia. Stratum plus 17, 221-244.

Slavinsky, V.S., Rybin, E.P., Khatsenovich, A.M., Belousova, N.E., 2019. Intentional fragmentation of blades in the initial upper Paleolithic industries of the Kara-Bom site (Altai, Russia). Archaeol. Res. Asia 17, 50-61.

Tabarev, A., Gunchinsuren, B., Gillam, J., Gladyshev, S.A., Dogand zi c, T., Zwyns, N., Bolorbat, T., Odsuren, D., 2012. Kompleks Pamiatnikov Kamennogo Veka v Doline r. Ikh TulberiinGol, Severnaya Mongolia (razvedochnye raboty s ispolzovaniem GIS-Technnologii v. 2011 g.)1. Studia Archaeol. Insit. Archaeol. Acad. Scient. Mongol. 32, 26-43.

Talamo, S., Richards, M., 2011. A comparison of bone pretreatment methods for AMS dating of samples $>30,000$ BP. Radiocarbon 53, 443-449.

Tashak, V., 2005. Hearths at the Podzvonkaya Paleolithic site: evidence suggestive of the spirituality of early populations of the Transbaikal region. In: Derevyanko, A.P. (Ed.), The Middle to Upper Paleolithic Transition in Eurasia: Hypotheses and Facts. Novosibirsk, pp. 405-413.

Teyssandier, N., Bon, F., Bordes, F., 2010. Within projectile range: some thoughts on the appearance of the aurignacian in europe. J. Anthropol. Res. 66, 209-221.

Turner, C.G., Ovodov, N.D., Pavlova, O.V., 2013. Animal Teeth and Human Tools, a Taphonomic Odyssey in Ice Age Siberia. Cambridge University Press. Vaquero, M., Romagnoli, F., 2018. Searching for lazy people: the significance of expedient behavior in the interpretation of paleolithic assemblages. J. Archaeol. Method Theor 25 (2), 334-367.

Vasiliev, S.G., Rybin, E.P., 2009. Tolbaga: upper paleolithic settlement patters in the transbaikal region. Archaeol. Ethnol. Anthropol. Eurasia 37, 13-34.

Villa, P., Mahieu, E., 1991. Breakage patterns of human long bones. J. Hum. Evol. 21, 27-48.

Weber, A., McKenzie, H.G., Beukens, R., Goriunova, O.I., 2005. Evaluation of radiocarbon dates from the middle Holocene hunter-gatherer cemetery khuzhir-nuge XIV, lake baikal, siberia. J. Archaeol. Sci. 32, 1481-1500.

Wrinn, P.J., 2010. Middle paleolithic settlement and land use in the Altai Mountains, siberia. In: Conard, N.J., Delagnes, A. (Eds.), Settlement Dynamics of the Middle Paleolithic and the Middle Stone Age, vol. III, pp. 163-194. Tubingen. 
Zwyns, N., 2012. Laminar Technology and the Onset of Upper Paleolithic in the Altai (Siberia). Leiden.

Zwyns, N., Lbova, L.V., 2019. The Initial Upper Paleolithic of Kamenka site, Zabaikal region (Siberia): a closer look at the blade technology. Archaeol. Res. Asia 17, 24-49.

Zwyns, N., Rybin, E.P., Hublin, J.J., Derevianko, A.P., 2012. Burin-core technology \& laminar reduction sequence in the initial upper paleolithic from kara-bom (Gorny- Altai, siberia). Quat. Int. 259, 33-47.

Zwyns, N., Gladyshev, S.A., Gunchinsuren, B., Bolorbat, T., Flas, D., Dogand zi c, T., Tabarev, A.V., Gillam, J.C., Khatsenovich, A.M., McPherron, S., Odsuren, D., Paine, C.H., Purevjal, K.-E., Stewart, J.R., 2014. The open-air site of Tolbor 16 (Northern Mongolia): preliminary results and perspectives. Quat. Int. 347, 53-65.

Zwyns, N., Paine, C.H., Tsedendorj, B., Talamo, S., Fitzsimmons, K.E., Gantumur, A., Guunii, L., Davakhuu, O., Flas, D., Dogand zi c, T., Doerschner, N., Welker, F., Gillam, J.C., Noyer, J.B., Bakhtiary, R.S., Allshouse, A.F., Smith, K.N., Khatsenovich, A.M., Rybin, E.P., Byambaa, G., Hublin, J.J., 2019. The northern route for human dispersal in central and Northeast Asia: new evidence from the site of tolbor-16, Mongolia. Sci. Rep. 9 (1), 1-10 